\title{
EDITORIAL
}

\section{A ESCRITA QUE NOS SALVA}

\author{
Denise Maurano ${ }^{1}$ \\ Joana Souza ${ }^{2}$ \\ Renata Mattos Avril ${ }^{3}$ \\ André Luis Lopes ${ }^{4}$
}

Estamos fechando esse ano, totalmente atípico, com a sensação de termos saído de uma grande batalha, de uma guerra que ainda resta vencer. Sairemos desse ano, mas certamente ele não sairá de nós. Luzes no final do túnel começam a surgir e, lentamente, vemos um fio de esperança de que o próximo ano seja um pouco mais leve, mais cheio de vida. Precisamos parar para respirar um pouco, ganhar forças e relançar o nó que enlaça o desejo que permite seguir caminhando, ainda que por caminhos nada tranquilos. A pandemia do COVID 19, nos transportou para uma realidade totalmente diferente, da qual só tínhamos notícias nos filmes de ficção científica. Nosso mundo se restringiu a uma grande sala virtual. É de lá que temos notícias dos amigos e familiares, que trabalhamos, namoramos, enfim, que vivemos uma vida possível. Fomos catapultados sem escalas, para o universo virtual. Passamos a habitar o planeta Web. Afinal, como a marca do desejo é a insistência, prosseguimos!

Em meio a tantas restrições, curiosamente, a psicanálise ganhou a oportunidade histórica de fazer valer sua contribuição tanto no âmbito clínico, quanto no cultural, de maneira ainda mais efetiva no universo cibernético. Frente às adversidades provocadas

\footnotetext{
1 Editora chefe do Periódico Psicanálise e Barroco em revista. Professora Titular aposentada do Universidade Federal do Estado do Rio de Janeiro. ORCID:https://orcid.org/0000-0003-3498-3773

2 Gerente de edição do Periódico Psicanálise e Barroco em revista. Doutora em Memória Social pela Universidade Federal do Estado do Rio de Janeiro. ORCID: https://orcid.org/0000-0003-4294-2883

${ }^{3}$ Editora da seção temática "A psicanálise, a voz, a memória e as musicalidades" com Pós-doutorado pela Universidade de Nice Sophia-Antipolis, Doutora em Pesquisa e Clínica em Psicanálise pela Universidade do Estado do Rio de Janeiro.

${ }^{4}$ Doutor em Pesquisa e Clínica em Psicanálise pela Universidade Estadual do Rio de Janeiro - UERJ.
} 
pela pandemia e ao horror que ela colocou em cena, nunca os psicanalistas foram tão demandados quer para intervirem clinicamente, quer para opinarem, fazerem lives, vídeo-conferências, artigos e manifestações em diversos âmbitos. A dimensão do real como impossível de ser controlado, ativou um nível de angústia que bem revelou a dimensão incomensurável de nossa fragilidade enquanto humanos. Fragilidade essa, da qual tentamos nos esquecer, via tantas garantias imaginárias, que bem se mostraram completamente impotentes para darem conta da continuidade da vida.

Há muitos anos atrás, Lacan fez uma declaração à France-Culture, a propósito do $28^{\circ}$. Congresso de Psicanálise, publicada pela Revista Le coq héron, em 1973, em Paris, no qual situou a psicanálise como o pulmão artificial de um mundo que se tornou irrespirável. Pois bem, cremos que jamais essa função Ihe caiu tão bem quanto nesses tempos de agora. Dentre tantas privações que nos foram impostas pelo confinamento exigido pela pandemia, encontrar o gozo no falar, tornou-se imperativo. O trabalho de luto, o peso das restrições, a saudade de tudo, vieram para frente da cena. Os atendimentos online ganharam uma legitimidade como nunca se tinha visto antes. A manutenção da potência da voz, a função do olhar, o manejo da transferência no trabalho clínico desafiou os analistas a se reinventarem na sua função mor de sustentar uma escuta diferenciada quer do que Ihes vinha da clínica quer do que observavam no contexto sócio-cultural.

Em meio a tudo isso, as publicações psicanalíticas ganharam destaque no mercado editorial, destacaram-se nas vendas, juntamente com as obras literárias. E é nesse clima ainda conturbado, dado que ainda não sabemos o que essa pandemia ainda vai nos exigir que lançamos mais esse número de nossa Revista. A publicação desta edição, testemunha o esforço de tantas pessoas que fizeram da escrita, um meio para atravessar esse momento turbulento que vivemos. Não tem sido fácil, mas quem disse que seria? Vida é insistência, é teimosia pura! Diante de tantas percas, vamos juntando o que resta e ver o que é possível criar. Foi com esse espírito que fechamos esta edição, que conta com artigos interessantíssimos.

Nossa seção temática apresenta, desta vez, dois escritos em torno da voz e da música sob perspectivas bem distintas, porém, ambos fazendo ressoar e modular o legado lacaniano. Temos, por um lado, a articulação entre música e literatura, ou melhor, uma bela reflexão sobre a presença da voz e da musicalidade na obra 
proustiana "Em busca do tempo perdido" para pensarmos a questão crucial da incidência de alíngua, lalangue, nos atos do sujeito. Por outro lado, encontramos o entrelaçamento entre voz, memória e transmissão na cultura afro-brasileira a partir da expressão do jongo. Neste, se destaca um traço de resistência e de saber fazer com o objeto pela via da criação que caracteriza bases da formação da nossa cultura e que, num momento de adversidades tão intensas como as que agora vivemos, é preciso colocar em primeiro plano. Nossa posição de psicanalistas inseridos e ativos no campo social, à escuta das singularidades e das pluralidades, nos engaja, pelo desejo, a invocar novos começos.

No escrito "Música, afeto, psicanálise", David Bernard, psicanalista francês e professor da Universidade de Rennes, parte da constatação frequentemente feita pelos analistas que se debruçam sobre as "poucas palavras" de Freud em relação à música para nos apresentar uma hipótese a este respeito. Para o autor, não se trataria de uma insensibilidade de Freud face à música. A bem conhecida afirmação freudiana, encontrada em "O Moisés de Michelangelo", quanto à sua incapacidade de analisar o que lhe afeta diante da escuta musical é tomada por Bernard como uma indicação dos efeitos deste afeto em Freud e da falta de um conceito teórico que lhe pudesse fazer avançar nas elaborações psicanalíticas acerca da criação e da fruição musical. $O$ autor localiza, assim, na teoria lacaniana a peça que faltaria à psicanálise para se colocar à escuta da música e da musicalidade estruturante dos sujeitos: lalangue.

Com Lacan, navegando entre o objeto voz e lalangue, Bernard nos leva a percorrer a célebre - e sempre a nos causar - obra de Marcel Proust "Em busca do tempo perdido", focalizando nos tempos do encontro amoroso entre Swann e Odette pontuados por uma peça musical, a "Sonata para piano e violino" de Vinteuil. O destaque será dado a uma frase desta sonata, que se colocará como o que despertará e orientará o amor, em suas diversas declinações e momentos, levando o autor a refletir sobre pontos fundamentais da psicanálise: a repetição, lalangue, o gozo, a memória, o enigma do real e de seus efeitos no sujeito, a voz, o dito e o que se encontra mais aquém ou além do dito, a significância, a presença/ausência no centro da dimensão linguajeira. Para tanto, Bernard constrói um diálogo entre Lacan, Proust e autores do campo da filosofia e da musicologia como Deleuze, Agambem, Dusapin, Strauss, 
Cohen-Levinas e Didi-Huberman. Um convite à ouvir o que a literatura nos ensina sobre a musicalidade constitutiva do falasser.

Já em "O jongo: voz, ritmo, memória e transmissão", Renata Mattos Avril nos convida a dançar a voz e a celebrar a memória enquanto força de transmissão e de resistência sociocultural. A autora visa articular e empreender um diálogo entre a vivência do jongo e a psicanálise, privilegiando o objeto voz ao abordar a manifestação cultural identitária do jongo na cultura afro-brasileira como possibilidade de criação do novo em torno da memória social.

Trata-se, portanto, de um artigo que se propõe a pensar e refletir sobre o jongo como um espaço de criação atrelado, nas palavras da autora, à "construção e transmissão de uma tradição enquanto memória viva de um grupo a partir da expressão rítmica e musical". Tendo em conta a voz, tal como a psicanálise lacaniana o conceitua em relação à constituição do sujeito, será, assim, tecida uma problematizando quanto à questão da memória. O que se mostra como uma contribuição de extrema importância para a psicanálise bem como para o pensamento descolonial ao abordar a função de criação de uma identidade coletiva, de laços sociais dos quais derivam uma produção estético-política, daí ser extremamente atual.

Abrindo a seção de artigos livres, o texto 0 des(p)ejo que me habita - a psicanálise e @s voltas, de autoria de Claudia aparecida de Oliveira Leite, resgata a importante obra «Quarto de despejo » de Carolina Maria de Jesus. Com precisão, a autora procura estabelecer uma instigante conexão entre o que Freud designa como sendo O Estranho (Das Unheimliche) e a estreita relação entre a escrita e o corpo, tematizadas por Carolina, sobre a qual testemunha em seu diário. O resgate da literatura também marca o escrito Forças antagônicas em Lavoura Arcaica de Raduan, escrito por Renato Tardivo, no qual procura destacar os antagonismos vividos pelo personagem André que se via preso entre o controle excessivo do pai e e o amor não menos excessivo da mãe. O autor destaca o embate entre a Lei do pai e o amor permissivo da mãe, destacando sua relação com a perversão. Em seguida, João Ezequiel Grecco, no artigo A paranoia do negro no Brasil, a análise de Arthur Ramos : uma relação entre identificação, crime e punição, retoma o discurso médico sobre o negro no Brasil, para interrogar a relação entre os fatores de degenerescência e miscigenação no que ele denomina de « paranoia do Negro no 
Brasil », como condição da catástrofe social. Discute a relação entre a constituição da paranoia como categoria clinica e a experiência estética social.

Rogério Lustosa Bastos discute a questão da visão freudiana e marcusiana da cultura e seus efeitos na subjetividade no artigo Freud-Marcuse, cultura e subjetividade: notas para um novo princípio de realidade. A partir de um abordagem acerca das coibições exercidas pela sociedade sobre o sujeito, o autor defende a ideia de que é essencial a recriação de um « Novo Princípio de Realidade » para haja uma mudança tanto na história quanto na subjetividade. Em As instituições psicanalíticas e suas formações sintomáticas, a psicanalista Betty Bernardo Fuks, estabelece uma importante análise acerca do ensino e transmissão da psicanálise a partir da importante frase freudiana «Eles não sabem o que estamos lhes trazendo: a peste ». Sua proposta é a de suscitar uma reflexão sobre os impasses sintomáticos presentes nas instituições psicanalíticas e sua influência sobre a formação de psicanalistas. Em seguida, temos o artigo A posição do psicanalista e seu desdobramento subjetivo no esquema L, escrito por Alberto Ramos Lautenchlager, cuja pretensão é a de investigar como acontece o desdobramento subjetivo do analista nos registros lacanianos do simbólico e do imaginário. O autor aponta que tanto o silêncio do analista quanto suas intervenções, evidenciam sua posição em relação aos extratos simbólicos e imaginários que compõe sua subjetividade. A relação entre a pulsão e o barroquismo na psicanálise é tematizado por André Fernando Gil Alcon Cabral em A pulsão em Freud e o barroco epistemológico. O autor defende a ideia da necessidade de se interpretar o conceito de pulsão pela perspectiva do barroco, para romper com o que ele denomina como « caráter fronteiriço da concepção freudiana ».

O artigo Manejo da arte na clínica da neurose, Beatriz de Oliveira Peixoto e Maycon Rodrigo da Silveira Torres, traz a perspectiva de que a arte é um elemento que produz espaço responsável por produzir o despendimento da palavra circunscrita e o alargamento de novas formas de expressão no humano, abrindo espaço para a experiência com o real. Em Feminilidade e modernidade em Freud : uma leitura crítica, Marcelo Ricardo Nolli empreende uma discussão acerca da relação entre modernidade e feminilidade, a partir do ele denomina como leitura crítica dos textos freudianos e sua relação com sua época. O autor defende que a teoria é um produto do seu tempo. Fechamos a seção com o artigo Tudo muda : uma leitura do contágio 
pela linguagem no filme "Pontypool » através da concepção freudiana sobre as afasias, de autoria de Felipe Akira Miasato, que trás uma interessante relação entre uma epidemia causada por uma infecçâo disseminada pela linguagem e a questão dos distúrbios da linguagem, tratados por Freud no ensaio "Afasias », onde apresenta o psiquismo como um aparelho de linguagem.

Fechamos essa edição com a resenha $\mathbf{A}$ constituição do personagem a partir do discurso e o eu iludido: identidade em sombra e violência invisível de Rafael Silveira que nos brinda com sua leitura sensível da obra O poder do discurso materno : Introdução à metodologia de construção da biografia humana, de Laura Gutman.

Convidamos nossos leitores a fazerem a experiência de adentrar nessa novíssima edição. Aproveitamos para lembrar a todos que seguimos com o fluxo contínuo de recepção de artigos, ensaios e resenhas para publicação mediante a aprovação de nossos pareceristas. 
RECEBIDO EM 20/11/2020

APROVADO EM 20/11/2020

(c) 2020 Psicanálise \& Barroco em revista

http://www.seer.unirio.br/index.php/psicanalise-barroco/index

revista@psicanaliseebarroco.pro.br

Programa de Pós-Graduação em Memória Social — UNIRIO

Memória, Subjetividade e Criação

www.memoriasocial.pro.br/proposta-area.php 